\title{
Kinetic modeling of enzymatic saccharification using wheat straw pretreated under autohydrolysis and organosolv process
}

\author{
Héctor A. Ruiz*, António A. Vicente, José A. Teixeira \\ IBB-Institute for Biotechnology and Bioengineering, Centre of Biological Engineering, University of Minho, Campus de Gualtar, 4710-057 Braga, Portugal
}

\section{A R T I C L E I N F O}

\section{Article history:}

Received 3 June 2011

Received in revised form 11 August 2011

Accepted 23 August 2011

Available online 24 September 2011

\section{Keywords:}

Enzymatic saccharification

Autohydrolysis

Organosolv

Wheat straw

\begin{abstract}
A B S T R A C T
The enzymatic saccharification kinetics of untreated wheat straw, pretreated solids obtained by a sequence of autohydrolysis (solubilization of hemicellulose) and organosolv (solubilization of lignin) were studied together with two pure cellulose model substrates, filter paper and Avicel. Two kinetic models for glucose production were compared and its kinetic constants calculated. According to the obtained results, enzymatic saccharification of the autohydrolysis pretreated solids (APS) proved to be more effective than when the organosolv pretreated solids (OPS) were used. The maximum extent of the enzymatic conversion of cellulose to glucose was $90.88 \%$ and $64.04 \%$, for APS and OPS respectively, at $96 \mathrm{~h}$. This result was probably due to an increase in accessible area for APS and a possible inhibition by phenolic acids deposited on the surface of OPS, acting as a barrier for enzymatic saccharification. Initial saccharification rate for APS and OPS was $0.47 \mathrm{~g} /(\mathrm{Lh})$ and $0.34 \mathrm{~g} /(\mathrm{Lh})$, respectively. Models based on first and second order cellulase deactivation kinetics satisfactory predicted the behavior of glucose production, however the second order model had a higher accuracy than the first order one. Visualization of structural modification induced by enzymatic saccharification at $12 \mathrm{~h}$ for the pretreated solids was done using scanning electron microscopy.
\end{abstract}

(c) 2011 Elsevier B.V. All rights reserved.

\section{Introduction}

Agricultural residues represent a major source of lignocellulosic material (LCM) with considerable potential for use in biomass conversion to ethanol. Wheat straw is one of the most abundant agricultural by-products in the world, has a low commercial value and a large part is applied as cattle feed and the rest as waste. In terms of total production, wheat is the second most important grain crop in the world. According to Food and Agriculture Organization of the United Nations (FAO, 2011) statistics reported a world annual wheat production in 2009 of 682 million tons and in average the production of $1.3 \mathrm{~kg}$ of the harvested grain is accompanied by the production of $1 \mathrm{~kg}$ of straw; this gives an estimation of about 524 million tons of wheat straw in 2009; these amounts are significant enough to consider wheat straw as a complementary source of raw material in the production of bioethanol (Petersen, 1988). One promising technology is to convert this abundant and renewable LCM to monomer sugars using enzymes that are to be applied after a pretreatment process and the microbes convert the sugars to ethanol. Enzymatic saccharification of cellulose is generally described as a heterogeneous reaction system in which cellulases in an aqueous environment react with the insoluble and struc-

\footnotetext{
* Corresponding author. Tel.: +351253604 400; fax: +351253678986.

E-mail address: hector_ruiz@deb.uminho.pt (H.A. Ruiz).
}

tured cellulose. According to the traditional enzyme classification system the cellulolytic enzymes are divided into three classes: (1) exo-1,4- $\beta$-D-glucanases or cellobiohydrolases (EC 3.2.1.91), which move processively along the cellulose chain and cleave off cellobiose units from the ends; (2) endo1,4- $\beta$-D-glucanases (EC 3.2.1.4), which hydrolyse internal $\beta$-1,4-glucosidic bonds randomly in the cellulose chain; and (3) 1,4- $\beta$-D-glucosidases (EC 3.2.1.21), which hydrolyse cellobiose to glucose and cleave of glucose units from cellooligosacharides. All these enzyme work synergistically to hydrolyse cellulose by creating new accessible sites for each other, removing obstacles and relieving product inhibition (Eriksson et al., 2002; Valjamae et al., 2003; Bansal et al., 2009). Consequently, these reactions can be affected by different obstacles as the use of high substrate concentrations, the presence of lignin, which shields the cellulose chains and adsorbed enzymes, crystallinity of cellulose, surface area, pore size, degree of polymerization (DP) and hemicellulose content (Chang and Holtzapple, 2000; Arantes and Saddler, 2010). In a recent work, Rollin et al. (2011) showed that improving the surface area accessible to cellulase is a more important factor than the removal of lignin for achieving a high sugar yield. However, due to the robust structure of LCM a pretreatment is required to alter the structural and chemical composition, improving the accessibility of the cellulose component to the action of hydrolytic enzymes so that an efficient hydrolysis of carbohydrates to fermentable sugars occurs (Zeng et al., 2007; Kim et al., 2008; Cybulska et al., 2010). 


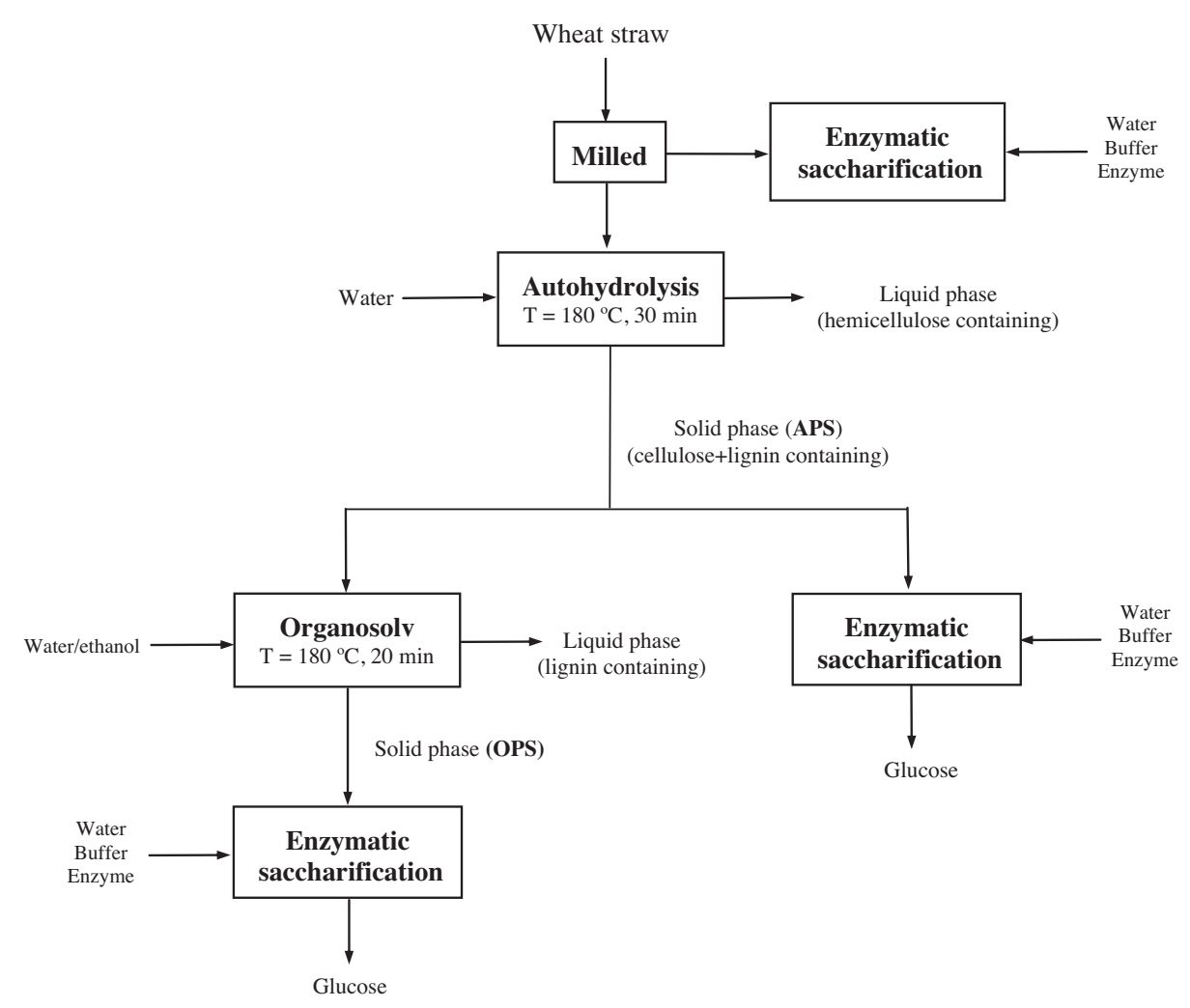

Fig. 1. Schematic representation of the sequence autohydrolysis and organosolv process.

Autohydrolysis or hydrothermal processing is an environmentally friendly process in which LCM is pretreated with just compressed hot water; it is based on the selective depolymerization of hemicellulose, which is catalyzed by hydronium ions generated in situ by water autoionization and by acetic acid from acetyl groups. Moreover, autohydrolysis pretreatment caused relocalization of lignin on the surface of LCM (Kristensen et al., 2008). This process avoids difficult steps in chemicals handling and recovery (e.g., sulfuric or hydrochloric acid) compared with dilute sulfuric acid or bases pretreatment (Garrote et al., 2008; Gullón et al., 2009; Díaz et al., 2010; Ruiz et al., 2011a). On the other hand, industrially, lignin is found during the process of papermaking from wood through of conventional or sulfur-containing lignins, which include kraft lignin and lignosulfonates. However, the major disadvantages of the kraft process include the low pulp yield, the high consumption of bleaching chemicals to obtain bright pulp, and formation of odorous gases (Ruiz et al., 2011a). In a previous work Ruiz et al. (2011b), isolated lignin using the organosolv process, having as result a production of partially pure and high quality lignin. This pretreatment, in which delignification of LCM is performed using an organic solvent (frequently ethanol) plus water, is an environmentally friendly chemical process compared with the kraft and sulfite processes (Young and Akhtar, 1997; Shirkolaee et al., 2008).

For the all mentioned above, the objective of present work was to investigate the susceptibility to enzymatic saccharification of pretreated solids after a sequence of autohydrolysis and organosolv process compared with untreated wheat straw and two model substrates (filter paper and Avicel) and to find an adequate model, using first and second order kinetics, to describe the enzymatic saccharification of the different substrates.

\section{Materials and methods}

\subsection{Raw material}

The wheat straw used in this study was kindly provided by a local farmer (Elvas, Portugal). Wheat straw was cut into small pieces $(1-3 \mathrm{~cm})$ and milled using a laboratory knife mill (Cutting Mill SM
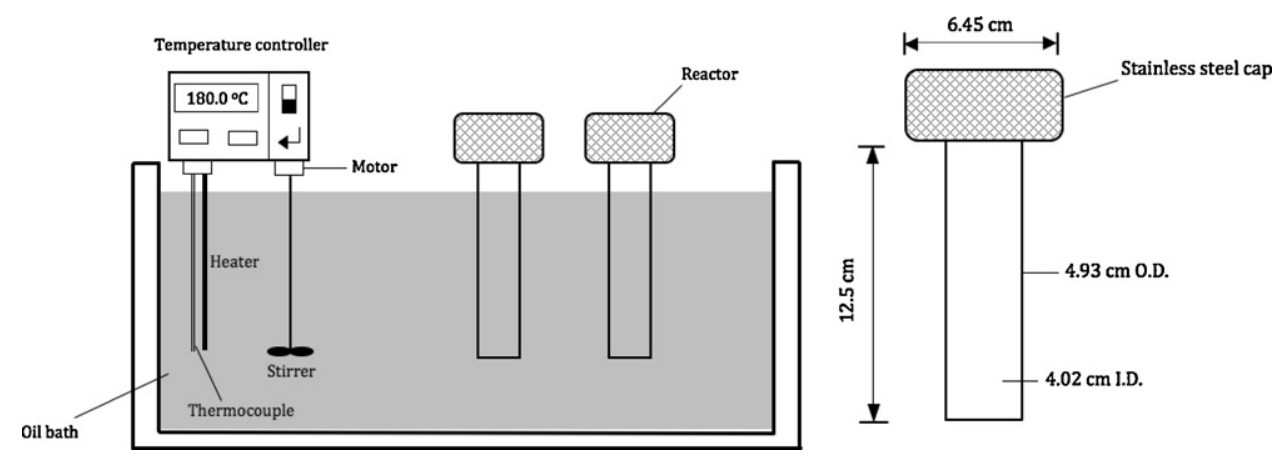

Fig. 2. Schematic of batch system for organosolv pretreatment. 
2000, Retsch, Germany). The material composition was previously analyzed by Ruiz et al. (2011a) and their particle size distribution (w/w\%) was as follows: $10 \%>1 \mathrm{~mm} ; 40 \%$ between 1 and $0.5 \mathrm{~mm}$; $40 \%$ between 0.5 and $0.3 \mathrm{~mm}$; and $10 \%$ to $<0.3 \mathrm{~mm}$.

\subsection{Wheat straw pretreatment by autohydrolysis process}

Milled wheat straw samples were mixed with water in order to obtain a $1: 10$ solid/liquid mass ratio and treated in a $3.75 \mathrm{~L}$ total volume stainless steel reactor (Parr Instruments Company, Moline, IL, USA) with PID temperature control. The moisture content of wheat straw was considered as water in the material balances. The reactor was filled and heated to $180^{\circ} \mathrm{C}$ at a heating rate of $3{ }^{\circ} \mathrm{C} / \mathrm{min}$ until reaching the desired temperature, the reaction time was $30 \mathrm{~min}$, these conditions having been previously evaluated by Ruiz et al. (2011a). After completing the reaction time, the reactor was cooled down at a rate of about $3.2^{\circ} \mathrm{C} / \mathrm{min}$ and the agitation speed was set at $135 \mathrm{rpm}$. At the end of the treatment, the liquid and solid phases were separated by centrifugation and the solid residues were washed several times with distilled water. The characterization and quantification of structural carbohydrates, sugars and degradation products in both solid and liquid phases has been previously reported by Ruiz et al. (2011b). Autohydrolysis was performed in order to achieve fractionation, mainly related to the selective removal of hemicelluloses and also to help solubilize the extract and facilitate the access by delignification reagents. The autohydrolysis pretreated solids (APS) were used as substrate for enzymatic saccharification and for delignification by organosolv process (see Fig. 1).

\subsection{Delignification by organosolv process}

The solid residue obtained after autohydrolysis pretreatment was delignified by the organosolv process using an aqueous solution of $40 \%(\mathrm{v} / \mathrm{v})$ ethanol and $0.1 \%(\mathrm{w} / \mathrm{v}) \mathrm{NaOH}$. The used conditions, previously defined (Ruiz et al., 2011b) for an efficient lignin removal from wheat straw were solid/liquid ratio: $1: 10(\mathrm{w} / \mathrm{v})$, temperature: $180^{\circ} \mathrm{C}$ and time: $20 \mathrm{~min}$. These experiments were carried out in batch cylinder reactors fabricated from 316 stainless steel having a length of $12.5 \mathrm{~cm}$, an outside diameter of $4.93 \mathrm{~cm}$, wall thickness $0.91 \mathrm{~cm}$ and a nominal volume of $160 \mathrm{~mL}$ (Fig. 2). The reactor was closed and mounted vertically and then submerged in a Julabo oil bath open heating circulator (JULABO Labortechnik GmbH, Seelbach, Germany) with temperature control, previously heated to the desired reaction temperature. At the end of the reaction, the reactor was removed from the oil bath and immediately cooled down by soaking in an ice-water bath for $5 \mathrm{~min}$. The residual solid material was separated via vacuum filtration and washed with distilled water. Quantification of structural carbohydrates of solid residue was performed according to the procedure reported by Ruiz et al. (2011b). The organosolv pretreated solids (OPS) were used as substrate for enzymatic saccharification.

\subsection{Enzyme}

Commercially available enzyme solutions, cellulase from Trichoderma reesei (Celluclast $1.5 \mathrm{~L}$ ) and $\beta$-glucosidase from Aspergillus niger (Novozyme 188), were kindly supplied by Novozymes A/S (Bagsvaerd, Denmark). The cellulase activity from Celluclast $1.5 \mathrm{~L}$ was analyzed in terms of FPU in accordance with the standard analytical methods established by the National Renewable Energy Laboratory (Adney and Baker, 1996). One unit of filter paper cellulase (FPU) was defined as the amount of enzyme which produces $2.0 \mathrm{mg}$ of reducing sugar from $50 \mathrm{mg}$ of filter paper within $1 \mathrm{~h}$. The experiment was carried out in a reaction mixture containing $0.5 \mathrm{~mL}$ of diluted enzyme solution, $1.0 \mathrm{~mL}$ of $50 \mathrm{mM}$ citrate buffer ( $\mathrm{pH} 4.8$ ), and $50 \mathrm{mg}$ of a $1 \mathrm{~cm} \times 6 \mathrm{~cm}$ strip of a Whatman No. 1 filter paper. The reaction solution was incubated at $50^{\circ} \mathrm{C}$ for $1 \mathrm{~h}$. Then the concentration of the released reducing sugar was measured using an adaption 3,5-dinitrosalicylic acid (DNS) method (Gonçalves et al., 2010). The $\beta$-glucosidase activity was determined for Novozyme 188 . The $\beta$-glucosidase activity was measured by incubating the enzyme solution with $4 \mathrm{mM} p$-nitrophenyl- $\beta$-D-glucopyranoside and $50 \mathrm{mM}$ sodium citrate buffer $\left(\mathrm{pH} \mathrm{4.8)}\right.$ at $30^{\circ} \mathrm{C}$ for $15 \mathrm{~min}$. The reaction was stopped by addition of $60 \mu \mathrm{L}$ of $1 \mathrm{M} \mathrm{Na}_{2} \mathrm{CO}_{3}$ and the amount of liberated $p$-nitrophenol measured spectrophotometrically at $400 \mathrm{~nm}$. One unit of activity (IU) was defined as the release of $1 \mu \mathrm{mol}$ of nitrophenol per minute. The enzyme activities of commercial concentrates were $43.05 \mathrm{FPU} / \mathrm{mL}$ for Celluclast $1.5 \mathrm{~L}$ and 576.39 UI/mL for Novozyme 188.

\subsection{Enzymatic saccharification}

The APS, OPS and untreated wheat straw were used as a substrate (Fig. 1) and two pure cellulose model substrates were carried out for comparison (a microcrystalline cellulose Avicel PH-101 and Whatman No. 1 filter paper). Enzymatic saccharification were performed in a jacketed glass reactor with a working volume of $50 \mathrm{~mL}$ (total volume of $75 \mathrm{~mL}$ ) at $50^{\circ} \mathrm{C}$ by duplicate, using cellulase (Celluclast $1.5 \mathrm{~L}$ ) and $\beta$-glucosidase (Novozyme 188) with a loading of $40 \mathrm{FPU} / \mathrm{g}$ and $60 \mathrm{IU} / \mathrm{g}$ of cellulose, respectively, in $50 \mathrm{mM}$ citrate buffer ( $\mathrm{pH} 4.8$ ) with $2 \%(\mathrm{w} / \mathrm{v})$ sodium azide to inhibit microbial contamination and a final cellulose concentration of $1 \%(\mathrm{w} / \mathrm{v})$ as described by Dowe and McMillan (2001) and Selig et al. (2008).

The necessary amount of deionized water was calculated and added to make the total volume of $50 \mathrm{~mL}$. Novozyme 188 was supplemented in order to eliminate the inhibition effect of cellobiose (Coward-Kelly et al., 2003). Agitation was carried out using a magnetic stirrer $(150 \mathrm{rpm})$ and samples were taken at $3 \mathrm{~h}$ intervals for the first $12 \mathrm{~h}$ and at $24 \mathrm{~h}$ intervals until a total time of $96 \mathrm{~h}$. The samples were kept in boiling water for $5 \mathrm{~min}$ to inactive enzymatic activity, and then centrifuged at $8260 \times g$ for $10 \mathrm{~min}$ to remove insoluble substrate; the supernatant was filtered through a $0.2 \mu \mathrm{m}$ sterile membrane filter analyzed for soluble sugars as described below.

The saccharification yield (\%) was calculated according to Eq. (1) (Dowe and McMillan, 2001).

Saccharification yield $(\%)=\frac{[\text { Glucose }]+1.053[\text { Cellobiose }]}{1.111 f[\text { Biomass }]} \times 100 \%$

where [Glucose] is glucose concentration $(\mathrm{g} / \mathrm{L})$, [Cellobiose] is cellobiose concentration $(\mathrm{g} / \mathrm{L})$, [Biomass] is dry biomass concentration at the beginning of the enzymatic saccharification $(\mathrm{g} / \mathrm{L}), f$ is cellulose fraction in dry biomass $(\mathrm{g} / \mathrm{g}), 1.111$ is the factor that converts cellulose to equivalent glucose and the factor 1.053 converts cellobiose to equivalent glucose.

\subsection{Analysis of sugars by HPLC}

Glucose and cellobiose were quantified by HPLC in a Jasco 880PU intelligent pump (Tokyo, Japan) chromatograph equipped with a refractive index detector and a Metacarb $87 \mathrm{H}(300 \mathrm{~mm} \times 7.8 \mathrm{~mm}$, Varian, USA) column. Chromatographic separation was performed under the following conditions: mobile phase $0.005 \mathrm{M} \mathrm{H}_{2} \mathrm{SO}_{4}$, flow rate $0.7 \mathrm{~mL} / \mathrm{min}$, and column temperature $60^{\circ} \mathrm{C}$. The volume injected was $20 \mu \mathrm{L}$ per sample. Sugars concentrations were determined using calibration curves obtained from standard solutions (Ruiz et al., 2011b).

\subsection{Modeling the kinetics of glucose production}

The kinetic model used in this work was proposed by Shen and Agblevor (2008a,b) and modified by Zhang et al.(2010). The models 
are function of three-constants that directly expresses the relationship between glucose production and two hydrolytic conditions (time and initial enzyme concentration). The assumptions of the model are: (1) cellulase enzyme containing endo- $\beta$-1,4-glucanase, exo- $\beta$-1,4-cellobiohydrolase and glycosidase and assuming a single combined effect in the hydrolysis of insoluble substrate; (2) surface structure of insoluble substrate was considered homogeneous. When cellulase deactivation is considered as a first order reaction, the model is as follow

$[P]=\left[S_{0}\right] \times\left\{1-\left[1-\frac{1-\exp \left(-k_{d e 1} t\right)}{1+\left(K_{e} /\left[E_{0}\right]\right)}\right]^{k_{2} / k_{d e 1}}\right\}$

And when cellulase deactivation is considered as a second order reaction, the mathematical model for sugars production is:

$[P]=\left[S_{0}\right] \times\left\{1-\left[1+\frac{K_{e}\left[E_{0}\right]}{K_{e}+\left[E_{0}\right]} k_{d e 2} t\right]^{-k_{2} /\left(K_{e} k_{d e 2}\right)}\right\}$

where $[p]$ is the glucose concentration $(\mathrm{g} / \mathrm{L}), t$ is the hydrolysis time, $\left[S_{0}\right]$ and $\left[E_{0}\right]$ represent initial substrate and enzyme $(\mathrm{g} / \mathrm{L})$, respectively, $K_{e}$ is the equilibrium constant $(\mathrm{g} / \mathrm{L}), k_{2}$ is the constant of product formation $\left(\mathrm{h}^{-1}\right), k_{d e 1}$ and $k_{d e 2}$ are the first order $\left(\mathrm{h}^{-1}\right)$ and second order $(\mathrm{L} /(\mathrm{h} \mathrm{g}))$ rate constants of cellulase deactivation. The glucose concentration profiles for first and second order reaction were fitted using the nonlinear regression analysis of POLYMATH 6.10 software (Polymath Software, Willimantic, CT, USA).

\subsection{Scanning electron microscopy}

The scanning electron microscopy (SEM) analysis was carried out to show morphological changes of enzymatic saccharification of pretreated solids. The images were visualized by a scanning electron microscope (Nova NanoSEM 200, Netherlands) and photographed. Samples were coated with a layer of gold by sputtering with an accelerating voltage varying to $5 \mathrm{kV}$.

\section{Results and discussion}

3.1. Effect of autohydrolysis and organosolv pretreatment on the composition of the solid phase

The chemical composition of APS, OPS, untreated wheat straw and two model substrates Avicel and filter paper are presented in Table 1. The initial composition of the wheat straw (untreated) showed that the cellulose (glucan) was the most abundant fraction (37.4\%), followed by hemicellulose (33.8\%) and Klason lignin (19.4\%), these values being in the range reported for wheat straw (Zabihi et al., 2010). The solid phase (APS) composition showed that the hemicellulose contents was reduced from 33.8 to $7.84 \%$ confirming the extensive removal caused by pretreatment; cellulose content was $63.7 \%$ and Klason lignin $26.91 \%$, revealing that the cellulose was almost not affected by the autohydrolysis process and a solid residue with increased cellulose and lignin concentration was obtained. These results are in agreement with Gullón et al. (2010) that observed a similar behavior for rye straw. The Klason lignin content follows a similar pattern to cellulose and the majority of the lignin content remained in the solid phase. The solid material obtained after autohydrolysis was delignified using the organosolv process, and a solid phase with cellulose content of $75.86 \%$ and $16.18 \%$ of the lignin was obtained, while the hemicellulose content was further reduced to $6.63 \%$. The partial delignification resulted in the removal of $38 \%$ of the Klason lignin. Moreover, the composition of Avicel and filter paper is showed in Table 1, containing more than 97 and $98 \%$ of cellulose, respectively. These model substrates have the advantage of not containing lignin (Kristensen et al., 2009). In recent studies Alfaro et al. (2009) reported that the susceptibility of different LCM to delignification depends on the content and
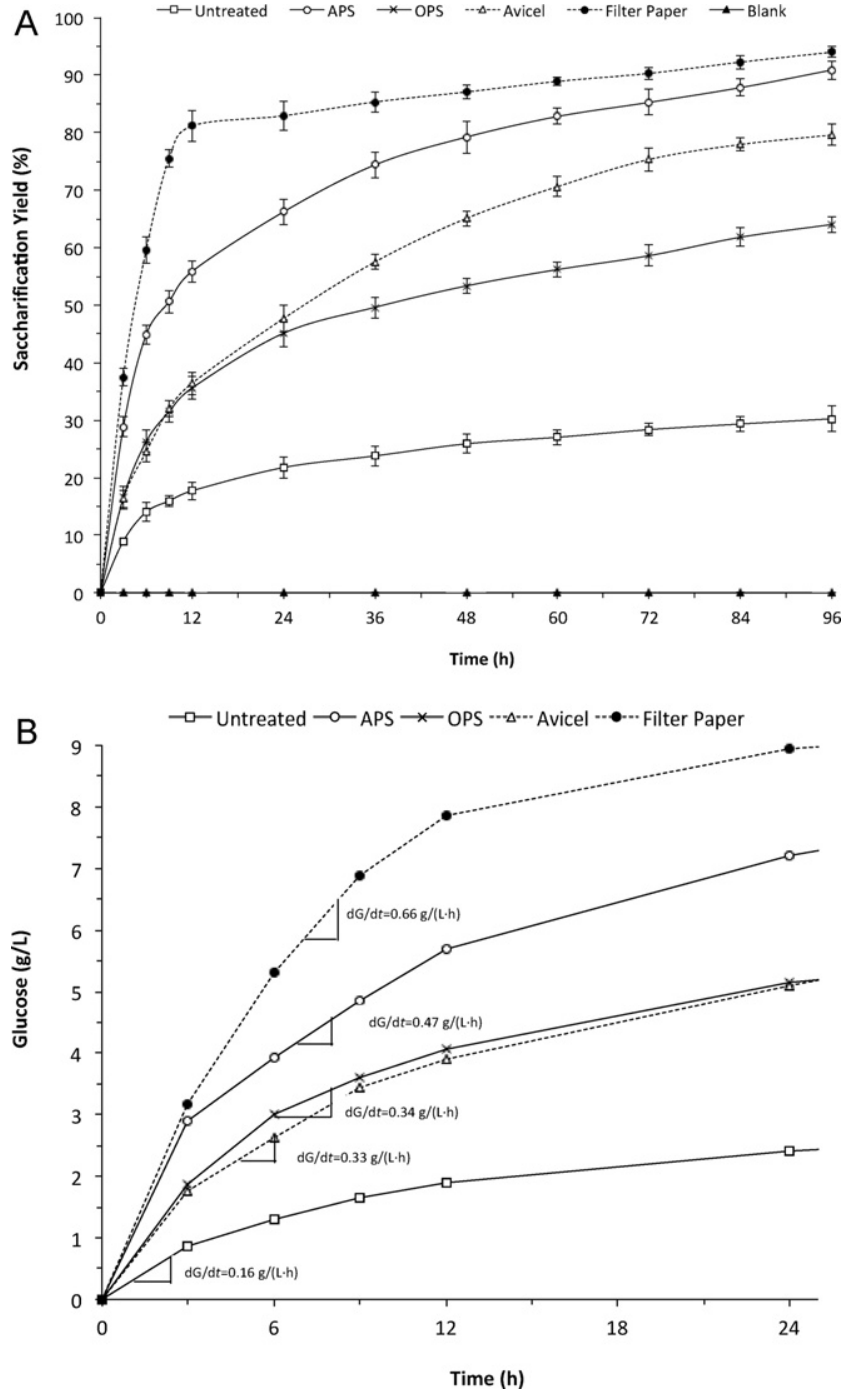

Fig. 3. Kinetic profile of enzymatic saccharification. (A) Saccharification yield of each substrate and (B) initial saccharification rate of each substrate. $\mathrm{d} G / \mathrm{d} t$ represents the initial saccharification rate calculated from the saccharification rate at $0-12 \mathrm{~h}$.

structural characteristics of lignin (syringyl and guayacyl units); also Hallac et al. (2010) reported a reduction of Klason lignin from Buddleja davidii of $37.19 \%$ at similar conditions of the described organosolv pretreatment using sulfuric acid as catalyst.

\subsection{Enzymatic saccharification of autohydrolysis and organosolv pretreated solids}

The profile of enzymatic saccharification yield (cellulose to glucose) is shown in Fig. 3A. The maximum saccharification yields were $90.88 \%, 64.04 \%$ and $30.36 \%$, for APS, OPS and untreated straw respectively, and were reached at $96 \mathrm{~h}$. For filter paper and Avicel, the obtained yields were $93.98 \%$ and $79.59 \%$ correspondingly. The saccharification yield of APS and OPS showed significant differences compared to the untreated wheat straw. The data indicated that the enzymatic saccharification yield was improved by autohydrolysis with similar values of saccharification yield have been reported (Lee et al., 2009) using the same pretreatment.

Díaz et al. (2010) reported a saccharification yield of 94.85\% using autohydrolysis pretreatment at severity conditions $\left(218.3^{\circ} \mathrm{C} / 30 \mathrm{~min}\right)$ and rapeseed straw as raw material. According to Zhao et al. (2009), the use of hydrothermal pretreatment caused the hemicellulose solubilization, allowing an improved enzymatic 
Table 1

Chemical composition, expressed as \% of dry matter, of untreated wheat straw and solid residues after autohydrolysis and organosolv treatment.

\begin{tabular}{|c|c|c|c|c|c|}
\hline Component & Untreated $^{\mathrm{a}}$ & Autohydrolysis ${ }^{\mathrm{b}}$ & Organosolv & Avicel $^{\mathrm{c}}$ & Filter paper ${ }^{\mathrm{d}}$ \\
\hline Cellulose & $37.4 \pm 0.9$ & $63.7 \pm 0.6$ & $75.86 \pm 0.93$ & $>97$ & $>98$ \\
\hline Hemicellulose & $33.80 \pm 0.5$ & $7.84 \pm 0.13$ & $6.63 \pm 0.25$ & & \\
\hline Klason lignin & $19.4 \pm 0.9$ & $26.91 \pm 0.39$ & $16.18 \pm 0.4$ & & \\
\hline Others ${ }^{\mathrm{e}}$ & $9.4 \pm 0.5$ & $1.55 \pm 0.86$ & $1.33 \pm 0.29$ & & \\
\hline
\end{tabular}

a Data published in Ruiz et al. (2011b).

b Data published in Ruiz et al. (2011a).

c Data published in Qing et al. (2010).

d Data published in Geng et al. (2010).

e Others components may include ash, protein and extractives.

saccharification yield, as enzyme accessibility to the LCM structure in the pretreated material is favored, increasing the potential of cellulose saccharification. Moreover, physical changes by autohydrolysis pretreatment that improve the enzymatic saccharification include an increase in pore size to enhance enzyme penetration and an increase in accessible area that has been shown to correlate well with the susceptibility of these substrates to enzyme saccharification (Liu and Wyman, 2005; Cybulska et al., 2010). Rollin et al. (2011) showed that improving the surface area accessible to cellulase is a more important factor for achieving a high sugar yield, suggesting that the amount of lignin remaining in the autohydrolysis solids is not a main obstacle for enzymatic saccharification.

On the other hand, the saccharification yield obtained from OPS (Fig. 3A) was lower compared with the obtained from APS. The delignification through organosolv pretreatment did not increase the saccharification. Similar values of saccharification yield (52.6\%) have been reported by Cara et al. (2006) using peroxide delignification after steam pretreatment. These results are in agreement with the data showed by Liao et al. (2005) for enzymatic saccharification of delignified manure.

To explain this behavior it has been suggested that during solid delignification using a physicochemical pretreatment as organosolv, lignin is often modified or degraded, resulting in demethylation and solubilization or formation of simple and oligomeric phenolics (Zhao et al., 2009). These phenolic acids are redeposited on the surface of the pretreated solid acting as a barrier for enzymatic saccharification (Anderson et al., 2008). In a previous work Ruiz et al. (2011b) reported the production of these phenolic acids compounds after applying the organosolv process in the delignification of wheat straw. Tejirian and Xu (2011) suggested that simple and oligomeric phenolics were the most inhibitory to enzymatic saccharification, being formed at inhibitory levels when biomass pretreatments are carried out at high solid level. According to Kim and Mosier (2009), the solubilization of lignin and lignin derived phenolic compounds during the pretreatment might have a negative impact on the action of enzymes during the hydrolysis due to unspecific binding of enzyme. Hodge et al. (2008) showed that the primary causes of inhibition of the enzyme action are the soluble compounds (acetic acid, phenolic compounds).

In respect to untreated wheat straw, a cellulose conversion yield $30.36 \%$ was obtained. Thus, the sequence of autohydrolysis and organosolv pretreatments increased saccharification compared to untreated wheat straw, which is in general agreement with literature data (Rémond et al., 2010). However, this sequential treatment proved to be less effective than the autohydrolysis with no further processing.

Complementary, the saccharification of APS and OPS was compared with the action of the enzymes in two model substrates, filter paper and Avicel, under the same conditions. These substrates are of course not identical to the LCM. However, these profiles allow observing the performance of the enzymes on pure cellulose substrate. Saccharification profiles of these model substrates are shown in Fig. 3A. Cellulose saccharification yield of filter paper was $93.98 \%$, while for Avicel was $79.59 \%$ at $96 \mathrm{~h}$. Therefore, knowing that the degree of polymerization (DP) of filter paper is much higher than the obtained with Avicel, Gupta and Lee (2009) showed that the DP of these substrates plays a significant role in enzymatic saccharification. The filter paper is more accessible to saccharification than APS, OPS, untreated wheat straw and Avicel. Moreover, the catalytic activity of the enzyme is controlled by the chemical characteristics of cellulose, for the case of Avicel with less DP and high crystallinity these being the main reasons for the sluggish saccharification (Gupta and Lee, 2009).

Results obtained in the present study are comparing favorably to those described in previous works (Bak et al., 2009; Kristensen et al., 2009). This in contrast with results published in our previous work (Ruiz et al., 2011b) reporting the crystallinity index for untreated wheat straw, APS and OPS. Crystallinity index of wheat straw increased after autohydrolysis pretreatment from $21.3 \%$ to $55.15 \%$ and a crystallinity index of $53.59 \%$ for organosolv pretreated solids was obtained. However, the increased crystallinity did not negatively affect the enzymatic saccharification of APS. Dogaris et al. (2009) reported an increased crystallinity of $48.16-58.38 \%$ for sorghum bagasse treated with hydrothermal processing. No significant correlation between crystallinity of pretreated solids from autohydrolysis and enzymatic saccharification was reported by Lee et al. (2010).

On the other hand, the initial saccharification rate $\mathrm{d} G / \mathrm{d} t$ is calculated from the saccharification that occurs in the first $12 \mathrm{~h}$ (the slope of glucose concentration vs time) and is shown in Fig. 3B. The initial saccharification rate of APS and OPS were $0.47 \mathrm{~g} /(\mathrm{Lh})$ and $0.34 \mathrm{~g} /(\mathrm{Lh})$, respectively. Untreated wheat straw had a low initial saccharification rate of $0.16 \mathrm{~g} /(\mathrm{Lh})$. With respect to the model cellulosic substrates filter paper and Avicel, the initial saccharification

Table 2

Model parameters from Eqs. (2) and (3) for the different kinetics of autohydrolysis and organosolv pretreated solids, untreated wheat straw, filter paper and Avicel.

\begin{tabular}{|c|c|c|c|c|c|c|c|c|c|c|}
\hline \multirow[t]{2}{*}{ Parameters } & \multicolumn{2}{|c|}{ Autohydrolysis } & \multicolumn{2}{|c|}{ Organosolv } & \multicolumn{2}{|c|}{ Untreated } & \multicolumn{2}{|c|}{ Filter paper } & \multicolumn{2}{|l|}{ Avicel } \\
\hline & Eq. (2) & Eq. (3) & Eq. (2) & Eq. (3) & Eq. (2) & Eq. (3) & Eq. (2) & Eq. (3) & Eq. (2) & Eq. (3) \\
\hline$K_{e}$ & 101.99 & 4.91 & 1010.99 & 9.93 & 238.79 & 97.63 & 273.69 & 0.25 & 808.99 & 0.904 \\
\hline$k_{2}$ & 0.45 & 0.11 & 3.50 & 0.14 & 0.20 & 0.17 & 3.11 & 0.59 & 2.92 & 0.05 \\
\hline$k_{d e 1}$ & 0.05 & - & 0.063 & - & 0.07 & - & 0.32 & - & 0.02 & - \\
\hline$k_{d e 2}$ & - & 0.079 & - & 0.068 & - & 0.05 & - & 0.23 & - & 0.06 \\
\hline$R^{2}$ & 0.981 & 0.999 & 0.976 & 0.999 & 0.975 & 0.999 & 0.995 & 0.996 & 0.983 & 0.991 \\
\hline$R^{2} a d j$ & 0.977 & 0.998 & 0.971 & 0.998 & 0.969 & 0.999 & 0.994 & 0.995 & 0.980 & 0.989 \\
\hline
\end{tabular}



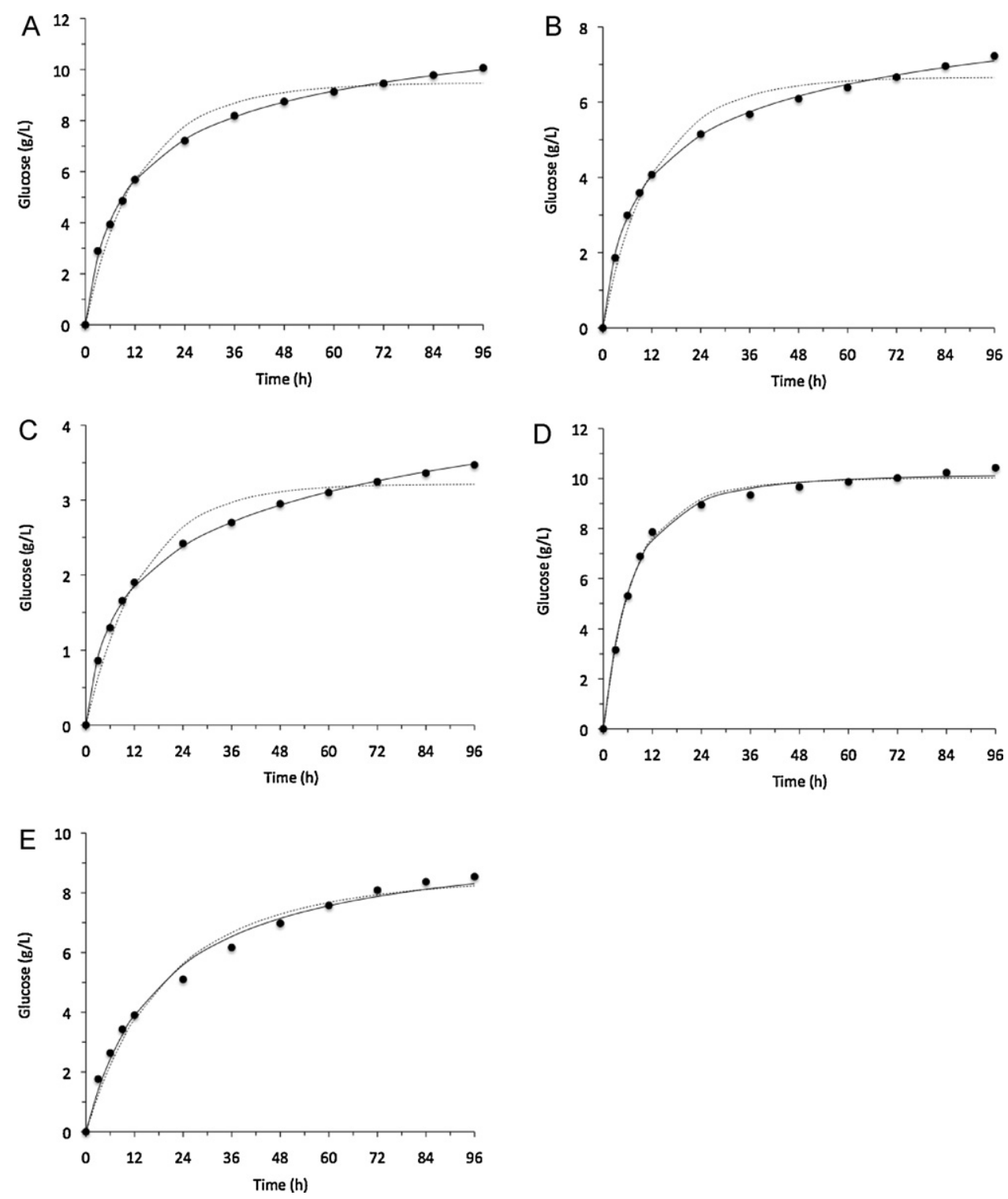

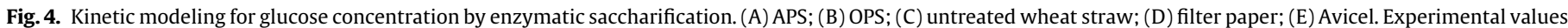
$(\bullet)$; modeling based on 1 st order reaction $(\cdots)$; modeling based on 2 nd order reaction $(-)$.

rate is $0.66 \mathrm{~g} /(\mathrm{Lh})$ and $0.33 \mathrm{~g} /(\mathrm{Lh})$, respectively. The APS significantly increases the saccharification rate, $56 \%$ of conversion being achieved at $12 \mathrm{~h}$, while the saccharification of OPS and Avicel had a similar performance achieving $35.59 \%$ and $36.42 \%$ of conversion, respectively, at the same $12 \mathrm{~h}$. Untreated wheat straw showed a conversion of $17.73 \%$ at $12 \mathrm{~h}$. Obviously, the filter paper achieves an $81.41 \%$ conversion, as might be expected from the comments mentioned above.

\subsection{Modeling of enzymatic saccharification}

The experimental glucose data concentration profiles of the enzymatic hydrolysis of different substrates, were fitted corresponding to the first and second order kinetic models, are shown in the Fig. 4A-E. The fitted constants $K_{e}, k_{2}, k_{d e 1}$ and $k_{d e 2}$ and the correlation coefficients $R^{2}$ are listed in Table 2 . In all cases, a good agreement with the experimental results was obtained (correlation coefficient, $R^{2}>0.97$ ). However, the correlation coefficient value $R^{2}$ for the second order kinetics is better than for the first order; the equilibrium constant $K_{e}$ and the constant of product formation $k_{2}$ for the second order model were smaller than for the first order, the first order $K_{e}$ value deviating greatly from the second order one; the constants of deactivation $k_{d e 1}$ and $k_{d e 2}$ were not significantly different. Therefore, the second order reaction models based on the correlation coefficient values $R^{2}$ for all substrates allow a satisfactory prediction of kinetic saccharification behavior. Zhang et al. (2010) also reported a better performance for the second order kinetic model than for the first order one on enzymatic saccharification.

\subsection{Scanning electron microscopy}

Differences in fiber structure between APS and OPS substrates are presented in Fig. 5A and B. SEM image of autohydrolysis (Fig. 5A) clearly shows a destruction of the fibers at $12 \mathrm{~h}$ of saccharification (56\% of saccharification yield and $0.47 \mathrm{~g} /(\mathrm{Lh})$ initial saccharification rate), demonstrating that the structure fiber was destroyed, explaining the behavior of the saccharification yield and glucose concentration. In the case of OPS, the saccharification efficiency and initial saccharification rate: $35.59 \%$ and $0.34 \mathrm{~g} /(\mathrm{Lh})$, 

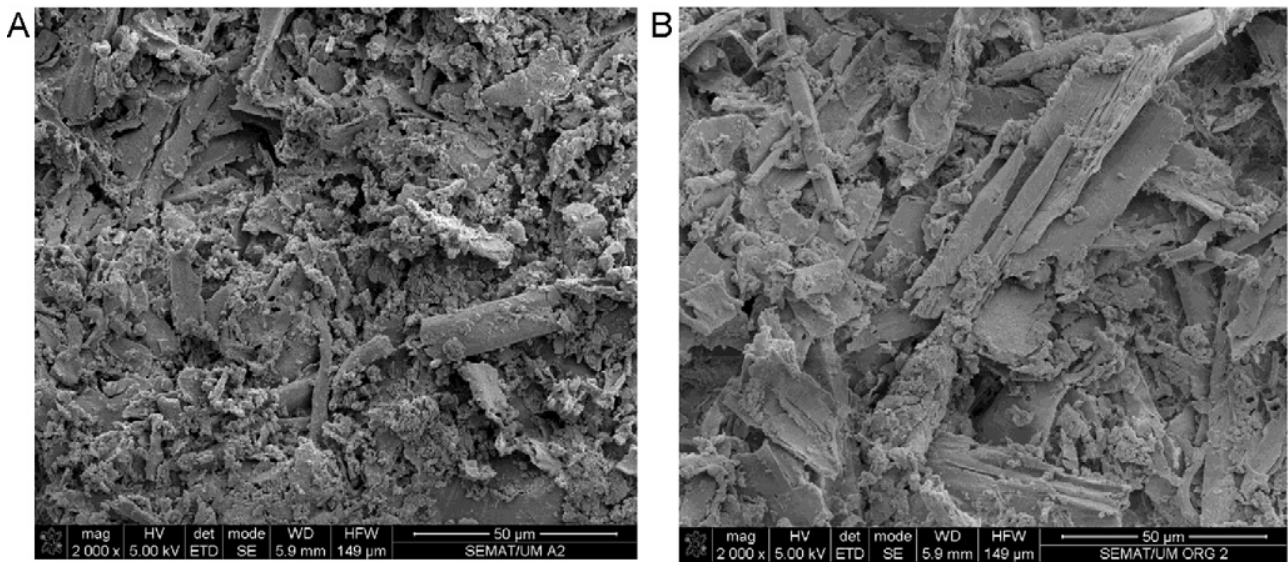

Fig. 5. SEM images of enzymatic saccharification at $12 \mathrm{~h}$. (A) APS and (B) OPS

respectively, were lower than the values presented for APS. These results together with images presented in Fig. 5A and B, where significant structural changes are observed, indicate once again the important role played by the above mentioned inhibitory products formed during the organosolv treatment on the saccharification reaction.

\section{Conclusions}

This work demonstrates the suitability of wheat straw treated by autohydrolysis or by autohydrolysis followed by organosolv process to enzymatic saccharification. Enzymatic saccharification conversion yield and reaction rate was higher for the autohydrolysis pretreated solids than for the solids subjected to a sequential autohydrolysis/organosolv treatment. The model based on the second order kinetics for cellulase deactivation was accurate on the description of the enzymatic saccharification process of all the studied substrates. This model can provide useful indications for the optimization of the kinetics of enzymatic saccharification of insoluble substrate for industrial applications.

\section{Acknowledgements}

The author H.A. Ruiz thanks to Mexican Science and Technology Council (CONACYT, Mexico) for PhD fellowship support (CONACYT ID 213592/308679), also to Professor Juan Carlos Parajó, Patricia Gullón and Beatriz Gullón from University of Vigo, for the assistance in the materials preparation under autohydrolysis process.

\section{References}

Adney, B., Baker, J., 1996. Measurement of Cellulase Activities. NERL/TP-510-42628. National Renewable Energy Laboratory, Golden, CO.

Alfaro, A., Rivera, A., Pérez, A., Yáñez, R., García, J.C., López, F., 2009. Integral valorization of two legumes by autohydrolysis and organosolv delignification. Bioresour. Technol. 100, 440-445

Anderson, W.F., Dien, B.S., Brandon, S.K., Peterson, J.D., 2008. Assessment of Bermuda grass and bunch grasses as feedstock for conversion to ethanol. Appl. Biochem. Biotechnol. 145, 13-21.

Arantes, V., Saddler, J.N., 2010. Access to cellulose limits the efficiency of enzymatic hydrolysis: the role of amorphogenesis. Biotechnol. Biofuels 3.

Bak, J.S., Ko, J.K., Han, Y.H., Lee, B.C., Choi, I.G., Kim, K.H., 2009. Improved enzymatic hydrolysis yield of rice straw using electron beam irradiation pretreatment. Bioresour. Technol. 100, 1285-1290.

Bansal, P., Hall, M., Realff, M.J., Lee, J.H., Bommarius, A.S., 2009. Modeling cellulase kinetics on lignocellulosic substrates. Biotechnol. Adv. 27, 833-848.

Cara, C., Ruiz, E., Ballesteros, I., Negro, M.J., Castro, E., 2006. Enhanced enzymatic hydrolysis of olive tree wood by steam explosion and alkaline peroxide delignification. Bioresour. Technol. 41, 423-429.

Chang, V.S., Holtzapple, M.T., 2000. Fundamental factors affecting biomass enzymatic reactivity. Appl. Biochem. Biotechnol. 84-86, 5-37.
Coward-Kelly, G., Aiello-Mazzari, C., Kim, S., Granda, C., Holtzapple, M., 2003. Suggested improvements to the standard filter paper assay used to measure cellulase activity. Biotechnol. Bioeng. 82, 745-749.

Cybulska, I., Lei, H., Julson, J., 2010. Hydrothermal pretreatment and enzymatic hydrolysis of prairie cord grass. Energy Fuels 24, 718-727.

Díaz, M.J., Cara, C., Ruiz, E., Romero, I., Moya, M., Castro, E., 2010. Hydrothermal pre-treatment of rapeseed straw. Bioresour. Technol. 101, 2428-2435.

Dogaris, I., Karapati, S., Mamma, D., Kalogeris, E., Kekos, D., 2009. Hydrothermal processing and enzymatic hydrolysis of sorghum bagasse for fermentable carbohydrates. Bioresour. Technol. 100, 6543-6549.

Dowe, N., McMillan, J., 2001. SSF Experimental Protocols-Lignocellulosic Biomass Hydrolysis and Fermentation. NERL/TP-510-42630. National Renewable Energy Laboratory Golden, CO.

Eriksson, T., Karlsson, J., Tjerneld, F., 2002. A model explaining declining rate in hydrolysis of lignocellulose substrates with cellobiohydrolase I (cel7A) and endogluconase I (cel7B) of Trichoderma ressei. Appl. Biochem. Biotechnol. 101, 41-60.

FAO (Organization of the United Nations), 2011. FAOSTAT Database, Available from: http://faostat.fao.org/site/567/DesktopDefault.aspx?PageID=567\#ancor.

Garrote, G., Yáñez, R., Alonso, J.L., Parajó, J.C., 2008. Coproduction of oligosaccharides and glucose from corncobs by hydrothermal processing and enzymatic hydrolysis. Ind. Eng. Chem. Res. 47, 1336-1345.

Geng, A., He, Y., Qian, C., Yan, X., Zhou, Z., 2010. Effect of key factors on hydrogen production from cellulose in a co-culture of Clostridium thermocellum and Clostridium thermopalmarium. Bioresour. Technol. 101, 4029-4033.

Gonçalves, C., Rodriguez-Jasso, R.M., Gomes, N., Teixeira, J.A., Belo, I., 2010. Adaptation of dinitrosalicylic acid method to microtiter plates. Anal. Methods 2 , 2046-2048.

Gullón, P., Pereiro, G., Alonso, J.L., Parajó, J.C., 2009. Aqueous pretreatment of agricultural wastes: characterization of soluble reaction products. Bioresour. Technol. $100,5840-5845$.

Gullón, B., Yáñez, R., Alonso, J.L., Parajó, J.C., 2010. Production of oligosaccharides and sugar from rye straw: a kinetic approach. Bioresour. Technol. 101, 6676-6684.

Gupta, R., Lee, Y.Y., 2009. Mechanism of cellulase reaction in pure cellulosic substrates. Biotechnol. Bioeng. 6, 1570-1581.

Hallac, B.B., Sannigrahi, P., Pu, Y., Ray, M., Murphy, R.J., Ragauskas, A.J., 2010. Effect of ethanol organosolv pretreatment on enzymatic hydrolysis of Buddleja davidii stem biomass. Ind. Eng. Chem. Res. 49, 1467-1472.

Hodge, D.B., Karim, M.N., Schell, D.J., McMillan, J.D., 2008. Soluble and insoluble solids contributions to high-solids enzymatic hydrolysis of lignocellulose. Bioresour. Technol. 99, 8940-8948.

Kim, Y., Hendrickson, R., Mosier, N.S., Ladisch, M.R., Bals, B., Balan, V., Dale, B.E. 2008. Enzyme hydrolysis and ethanol fermentation of liquid hot water and AFEX pretreated distillers' grains at high solids loadings. Bioresour. Technol. 99, 5206-5215.

Kim, Y., Mosier, N.S., 2009. Enzymatic digestion of liquid hot water pretreated hybrid poplar. Biotechnol. Prog. 25, 340-348.

Kristensen, J.B., Thygesen, L.G., Felby, C., Jørgensen, H., Elder, T., 2008. Cell-wall struc tural changes in wheat straw pretreated for bioethanol production. Biotechnol. Biofuels 1, 5 .

Kristensen, J.B., Felby, C., Jørgensen, H., 2009. Yield-determination factors in highsolids enzymatic hydrolysis of lignocellulose. Biotechnol. Biofuels 2, 11 .

Lee, J.M., Shi, J., Venditti, R.A., Jammel, H., 2009. Autohydrolysis pretreatment of coastal Bermuda grass for increased enzyme hydrolysis. Bioresour. Technol. 100 6434-6441.

Lee, J.M., Jameel, H., Venditti, R.A., 2010. A comparison of the autohydrolysis and ammonia fiber explosion (AFEX) pretreatments on the subsequent enzymatic hydrolysis of coastal Bermuda grass. Bioresour. Technol. 101, 5449-5458.

Liao, W., Wen, Z., Hurley, S., Liu, Y., Liu, C., Chen, S., 2005. Effects of hemicellulose and lignin on enzymatic hydrolysis of cellulose from dairy manure. Appl. Biochem. Biotechnol. 121-124, 1017-1030. 
Liu, C., Wyman, C.E., 2005. Partial flow of compressed-hot water through corn stover to enhance hemicellulose sugar recovery and enzymatic digestibility of cellulose. Bioresour. Technol. 96, 1978-1985.

Petersen, P.B., 1988. Separation and characterization of botanical components of straw. Agric. Prog. 63 (8), 23.

Qing, Q., Yang, B., Wyman, C.E., 2010. Xylooligomers are strong inhibitors of cellulose hydrolysis by enzymes. Bioresour. Technol. 101, 9624-9630.

Rémond, C., Aubry, N., Crônier, D., Noël, S., Martel, F., Roge, B., Rakotoarivonina, H., Debeire, P., Chabbert, B., 2010. Combination of ammonia and xylanases pretreatment: Impact on enzymatic xylan and cellulose recovery from wheat straw. Bioresour. Technol. 101, 6712-6717.

Rollin, J.A., Zhu, Z., Sathitsuksanoh, N., Zhang, Y.H.P., 2011. Increasing cellulose accessibility is more important than removing lignin: a comparison of cellulose solvent-based lignocellulose fractionation and soaking in aqueous ammonia. Biotechnol. Bioeng. 108, 22-30.

Ruiz, H.A., Ruzene, D.S., Silva, D.P., Quintas, M.A.C., Vicente, A.A., Teixeira, J.A., 2011a. Evaluation of a hydrothermal process for pretreatment of wheat straweffect of particle size and process conditions. J. Chem. Technol. Biotechnol. 86, 88-94.

Ruiz, H.A., Ruzene, D.S., Silva, D.P., Silva, F.M.D., Vicente, A.A., Teixeira, J.A., 2011b. Development and characterization of an environmentally friendly process sequence (autohydrolysis and organosolv) for wheat straw delignification. Appl. Biochem. Biotechnol. 164, 629-641.

Selig, M., Weiss, N., Ji, Y., 2008. Enzymatic Saccharification of Lignocellulosic Biomass. NERL/TP-510-42629. National Renewable Energy Laboratory Golden, CO.
Shen, J., Agblevor, F.A., 2008a. Optimization of enzyme loading and hydrolytic time in the hydrolysis of mixtures of cotton gun waste and recycled paper sludge for the maximum profit rate. Bioresour. Technol. 41, 241-250.

Shen, J., Agblevor, F.A., 2008b. Kinetic of enzymatic hydrolysis of steam-exploded cotton gin waste. Chem. Eng. Commun. 195, 1107-1121.

Shirkolaee, Y.Z., Rovshandeh, J.M., Charani, P.R., Khajeheian, M.B., 2008. Influence of dimethyl formamide pulping of wheat straw on cellulose degradation and comparison with kraft process. Bioresour. Technol. 99, 3568-3578.

Tejirian, A., Xu, F., 2011. Inhibition of enzymatic cellulolysis by phenolic compounds. Enzyme Microb. Technol. 48, 239-247.

Valjamae, P., Kipper, K., Pettersson, G., Johansson, G., 2003. Synergistic cellulose hydrolysis can be described in terms of fractal-like kinetics. Biotechnol. Bioeng. 84, 254-257.

Young, R.A., Akhtar, M., 1997. Environmentally Friendly Technologies for the Pulp and Paper Industry, first ed. Wiley, New York.

Zabihi, S., Alinia, R., Esmaeilzadeh, F., Kalajahi, J.F., 2010. Pretreatment of wheat straw using steam, steam/acetic acid and steam/ethanol and its enzymatic hydrolysis for sugar production. Biosyst. Eng. 105, 288-297.

Zeng, M., Mosier, N.S., Huang, C., Sherman, D.M., Ladish, M.R., 2007. Microscopic examination of changes of plant cell structure in corn stover due to hot water pretreatment and enzymatic hydrolysis. Biotechnol. Bioeng. 97, 265-272.

Zhang, Y., Xu, J.G., Xu, H.J., Yuan, Z.H., Guo, Y., 2010. Cellulase deactivation based kinetic modeling of enzymatic hydrolysis of steam-exploded wheat straw. Bioresour. Technol. 101, 8261-8266.

Zhao, X., Cheng, K., Liu, D., 2009. Organosolv pretreatment of lignocellulosic biomass for enzymatic hydrolysis. Appl. Biochem. Biotechnol. 82, 815-827. 